\title{
Review of A Real Multi-story Store Fire by Applying Evacuation and Smoke Movement Interactive Simulation Model
}

\author{
AI SEKIZAWA, SHUJI KAKEGAWA and MANABU EBIHARA \\ University of Tokyo \\ Building 9, 2-11-16 Yayoi, Bunkyo-ku, Tokyo 113-8656, Japan \\ Institute of Technology, Shimizu Corporation \\ 3-4-17, Etchujima, Koto-ku, Tokyo, 135-8530, Japan \\ Tokyo University of Science \\ 2641 Yamazaki, Noda-shi, Chiba, 278-8510, Japan
}

\begin{abstract}
The evacuation and smoke movement interactive simulation model has been developed to handle the evacuation of large populations of individuals with mixed walking capabilities. The advantages of the model are: 1) to handle evacuation of individual evacuees considering variety of behavioral parameters, 2) to handle total evacuation in a multi-story building via the stairs, and 3) to consider interactions between egress behavior and spread of smoke in a building. The system is a deterministic simulation program implemented by the agent-based computer language, Repast. Using this simulation model, we conducted case studies to reproduce the smoke condition and evacuation situation of a real fatal fire of the 1990 Nagasakiya-Amagasaki Store Fire as accurately as possible reflecting the facts from the survey. The calculated results of case studies well agreed with the investigated pattern of risk in evacuation behavior linked with the smoke impacts by the model. We also demonstrated that our simulation model is useful enough to examine possible changes of consequences according to different egress scenarios in order to find possible future issues and solutions for the problems regarding the total evacuation in a multi-story building.
\end{abstract}

KEYWORDS: evacuation, simulation, smoke movement, interactive model

\section{NOMENCLATURE LISTING}

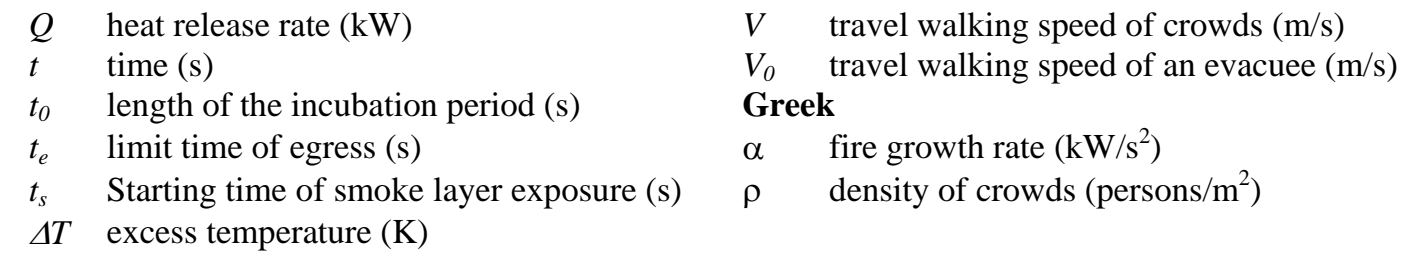

\section{INTRODUCTION}

Large buildings such as high-rises and commercial complexes present a risk of evacuating all the occupants during a fire taking a long time as seen in the explosion of the World Trade Center in 1993[1]. Also, a wide variety of people behave differently during emergency escape according to their age and physical capacity. To predict behavior in evacuation under such conditions, modeling the behavior of individuals according to their attributes is necessary. Exodus[2], Simulex[3] and other models are presently available for predicting individual behavior in evacuation. The authors have developed calculation models for predicting the evacuation of occupants who exhibit varying escape patterns $[4,5,6]$. As one of the important aspects of predicting evacuation throughout a multi-story building is the modeling of occupants' behavior in staircases, so the authors improved calculation algorithms for the evacuation model in staircases to well duplicate it.

In this paper, we first introduced the facts from our survey of evacuation situation and smoke condition in a real fatal fire of the 1990 Nagasakiya-Amagasaki Store for the reference of the premises of the calculation in the case study, which is even alone very informative to understand the behavioral features of occupants in a real fire. Then, using our simulation model, we conducted case studies to reproduce the smoke condition and evacuation situation of this fatal fire as accurately as possible reflecting the facts of this fire. We also tried to examine possible changes of consequences according to different egress scenarios in order 
to find possible future issues and solutions for the problems regarding the total evacuation in a multi-story building by applying the model to the Nagasakiya Store fire.

\section{EVACUATION IN THE 1990 NAGASAKIYA STORE FIRE}

The Nagasakiya Store fire occurred in March 18, 1990 in Amagasaki city in Japan. The fire occurred in the sales floor of bedding on the $4^{\text {th }}$ floor and spread throughout the floor in about ten minutes. The heat and smoke entered the $5^{\text {th }}$ floor and the third and lower floors via two staircases and an elevator shaft. Occupants in the offices and the employee dining room on the $5^{\text {th }}$ floor failed to start evacuation early and were forced to take refuge on the floor. High-temperature smoke spread to the $5^{\text {th }}$ floor and killed 15 occupants. Desperate rescue efforts saved four people through windows. At that time, the authors had a chance to have interviews with several key employees as well as the fire officials and obtained very detailed information of the reaction and human behavior in the fire along with fire growth and smoke condition. This kind of information on human behavior in a real fire must be very useful to advance the research of verification of the models for evacuation and smoke movement as well as the knowledge of psychological and behavioral reaction of occupants in a fire.

\section{Outline of the Building}

The Nagasakiya Store is a reinforced concrete retail store with five floors above ground and one basement floor. A typical floor has a floor area of $814 \mathrm{~m}^{2}$, and the total floor area is $5,140 \mathrm{~m}^{2}$. The sales space occupies the first through $4^{\text {th }}$ floors. The $5^{\text {th }}$ floor accommodates a game arcade, emergency service office, storages and an employee dining room. (See Fig.1)

The north and south staircases are located in the northeast corner (staircase- $\mathrm{N}$ ) and the southeast corner (staircase-S) of a plan respectively. All floors other than $5^{\text {th }}$ floor are open-floor that directly connects the two staircases and an escalator that services from the first floor to the $4^{\text {th }}$ floor located in the west side. The doors between floors and staircases were automatic closing fire doors activated by smoke detectors, but the fire door of the staircase- $\mathrm{N}$ on the $5^{\text {th }}$ floor was actually blocked to close with a big luggage in front of the door. Shoppers usually used the escalator for their movement between floors and they rarely used the staircase-N because it is invisible to them and usually used exclusively by employees. No sprinkler system was installed in this building.

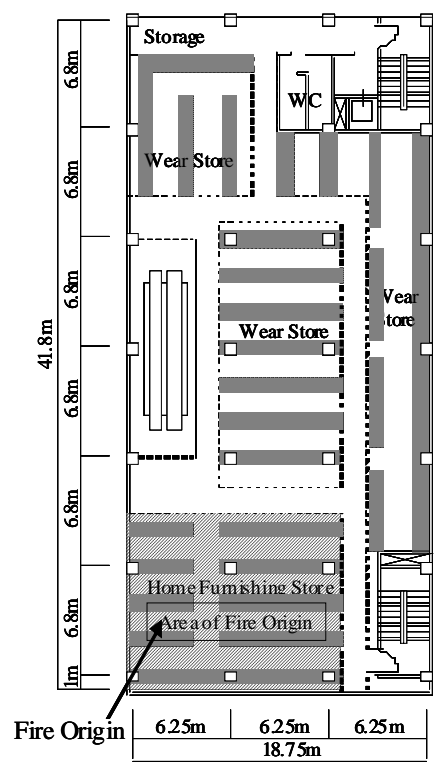

(a) Forth floor (fire origin floor)

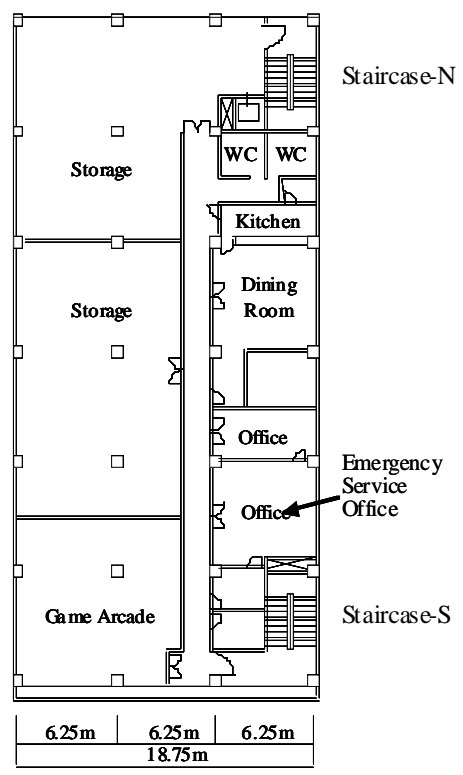

(b) Fifth floor

Fig. 1. Plan of the Amagasaki store of Nagasakiya. 


\section{Reaction of the occupants along with the progress of fire and smoke}

The fire was perceived by the smoke alarm system even before the employee near the fire origin found it, but it quickly became a flaming fire and developed further to result in flashover on the $4^{\text {th }}$ floor within about 10 minutes and then poured out the heavy smoke to both the north and the south staircases, as it was started as a suspicious fire. As for the $4^{\text {th }}$ floor and lower floors, evacuation guidance to the occupants was done quite swiftly by the salesclerks and all of the occupants got out of the building safely. However, on the $5^{\text {th }}$ floor, as the employees and other occupants were not properly notified of the fire by the staff in the emergency service office, they misjudged the fire condition and failed to start their evacuation in time and then were trapped in the dining room except the only one employee who went down to $4^{\text {th }}$ floor at once due to being impelled by duty when she was told that the fire stared at her station. This fire gave us the lesson that early proper notification of a fire and evacuation guidance without any normalcy bias is very important especially for responsible emergency staff, as a fire may develop far more quickly than they expect. The reaction of occupants along with the progress of fire and smoke in the fire is summarized in Fig.2 based on the data from the reports $[7,8]$. The following are the detailed features of behavioral reaction by time lapse and by each floor.

The first recognition of the fire [12:32 - 12:33]

Around 12:30, a suspicious fire started near the sales space of bedding on the 4th floor. The sign of the fire was recognized by the smoke detector and its signal was transmitted to the emergency service office on the $5^{\text {th }}$ floor and the alarm sounded at 12:32. Shortly after the staff in the emergency service office realized the activation of smoke detectors on the receiving set, they made a call to the employee (C) near the activation spot to make sure of whether or not it was a real fire. During the talk with the staff on telephone, the employee (C) witnessed the flame standing up roughly $1 \mathrm{~m}$ on the hanging curtain and answered that it was a real fire, which means that the recognition of the fire was done at latest around 12:33, which was roughly estimated one minute after the smoke detector activation. The problem begins with reaction of the staff and employees in the dining room on the $5^{\text {th }}$ floor after then.

\section{The first reaction after the recognition of the fire [12:33 - 12:38]}

The employees on the $4^{\text {th }}$ floor quickly started the guidance of evacuation of guests on the floor and then tried to suppress it with portable extinguishers because they themselves saw and confirmed the fire. On the other hand, the staff in the emergency service office on the $5^{\text {th }}$ floor did not see the fire by themselves and indirectly recognized it on the telephone talk with the employee (C) on the $4^{\text {th }}$ floor. So then, they first tried to call their superior manager in code language over the P.A. system according to the manual, but they did not quickly start the announcement about emergency evacuation to all the occupants in the building, although they already knew the occurrence of the real fire through the fire alarm system and the employee on the $4^{\text {th }}$ floor. And, the employees, who were taking the rest in the dining room on the $5^{\text {th }}$ floor, were not informed of the fire by the staff until the threat of the fire almost arrived at them around 12:38, five minutes after the staff in the emergency service office realized the fire.

Out of the employees in the dining room on the $5^{\text {th }}$ floor, who were informed of the fire around 12:38, only one employee (F) went down to staircase- $\mathrm{N}$ right after the notice and survived. However, this was because she was in charge of the sales floor of bedding where the fire started and afterwards she confessed that she went down to the $4^{\text {th }}$ floor not for her own safe evacuation but simply for being impelled by duty.

The rapid fire growth stage until the limit of evacuation due to the flashover [12:38 - 12:42]

The employee (F) met up with the evacuees running away from the 4th floor when she came down to that floor by the staircase-N. Then, she rundown further together with those people and survived. The employee (F) said the black smoke just started to pour from the 4th floor into the staircase- $\mathrm{N}$ and very soon later the staircase- $\mathrm{N}$ was no longer possible to use for evacuation (roughly estimated at 12:40-12:42). On the other hand, the twenty-one people, who remained staying on the 5th floor even after the notice of the fire, became too late to go down by stairs after that time. Out of these remaining occupants, two people jumped down from the window of the dining room and four people were rescued by firefighters with a portable ladder from the roof of an adjacent building, but this rescue became impossible due to the heavy smoke in the room after then. These six people survived and the remaining fifteen were killed by the fire. 


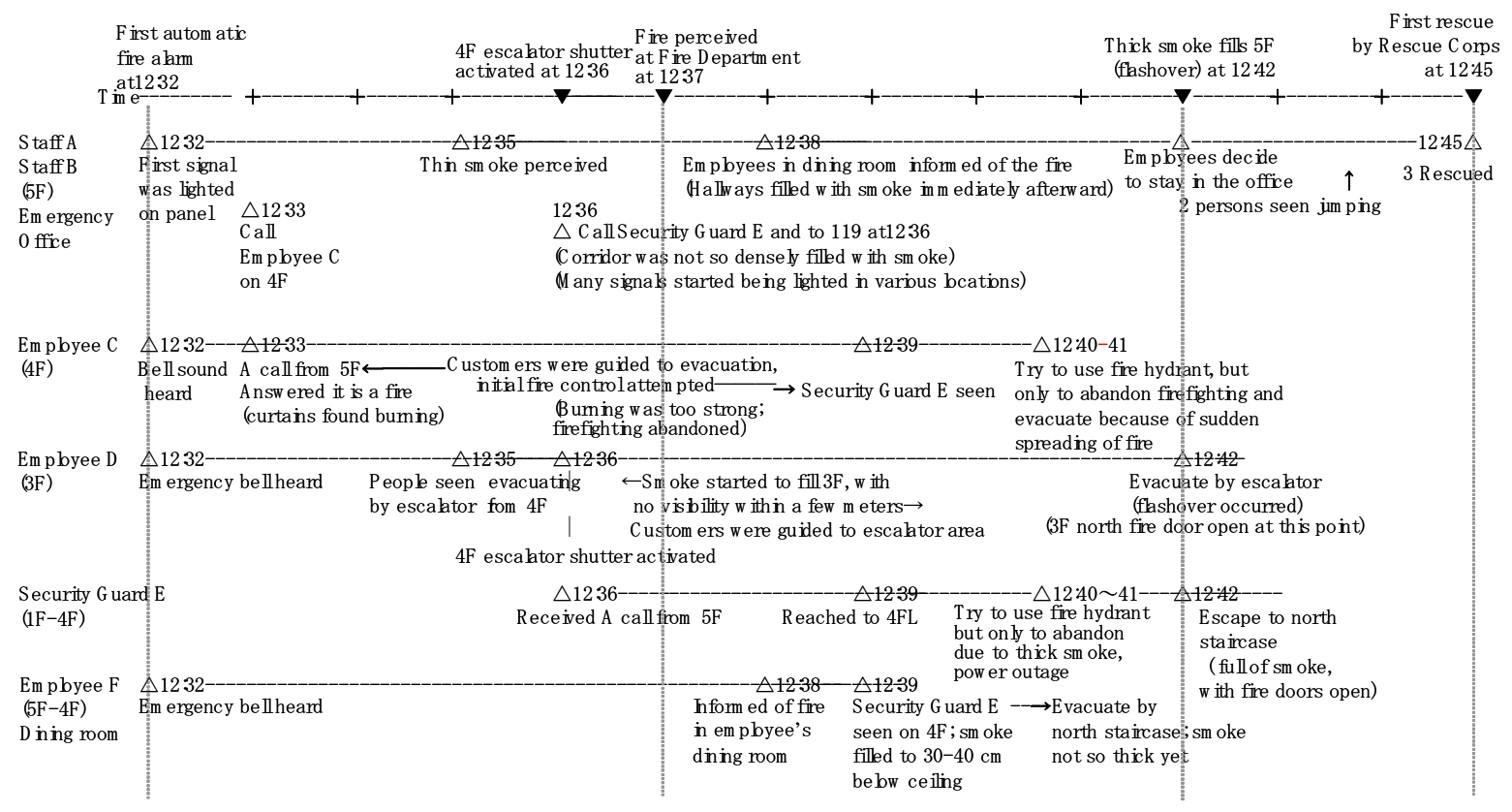

Fig. 2. Outline of fire/smoke condition and corresponding human behavior in the Nagasakiya Store fire.

\section{EVACUATION MODEL}

Individual behavior of evacuation in the model is represented using Repast, an agent-based simulation toolkit. The model is composed of three sub-models such as space model, human model, and smoke model as shown in Fig.3. The features regarding the evacuation model are as follows.

- Walking on slopes at given angles has been formulated to model walking in the staircase.

- Obstacles to walking in the room such as furnishings and the behavior to get around them have been modeled.

- Selecting the destination based on the congestion around it has been made possible.

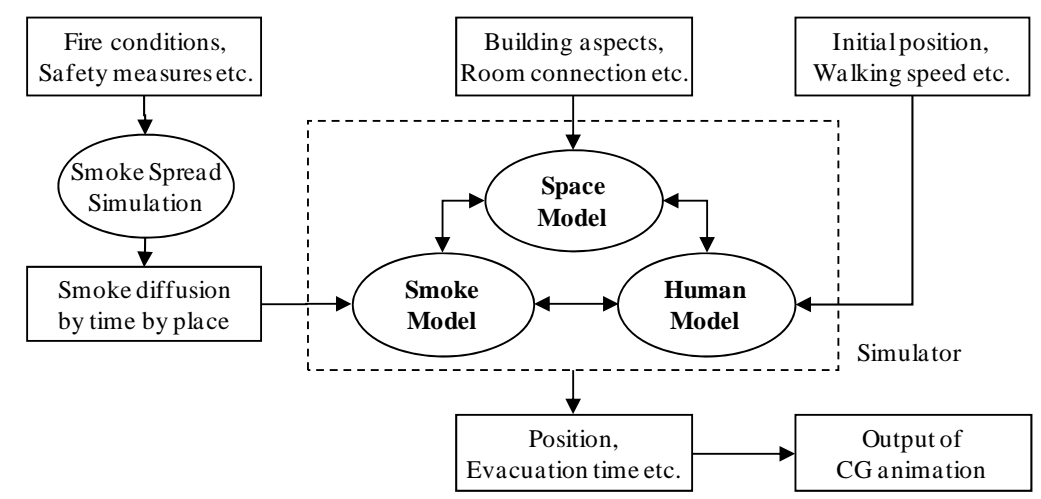

Fig. 3. Composition of evacuation and smoke movement interactive model.

\section{Space Model}

The space model is a model of each space constituting the building for predicting evacuation. A building is regarded as an aggregate of rooms and corridors that are virtual spaces enclosed by openings and walls. Fig.4 shows the concept of modeling space in a building. Enclosed spaces are connected to each other via openings to model all the spaces in the building.

Enclosed spaces including a staircase can be divided into several areas. The angle and direction of slope of the floor can be separately specified in each area using gradient vectors. Thus, staircases and spaces with 
sloped floor in the building are modeled. Fig.5 shows the concept of modeling space in staircase. Staircases are connected to multiple floors via landing. No staircases are therefore modeled as one room from the first floor to the top floor. Each story is modeled as a base unit of the staircase. Multiple stories are connected to one another via virtual openings. In the former models, no effects of evacuees taking a spiral course via landing can be taken into consideration. However, a staircase in a story, a base unit, is now divided into four cells, two landings and two flights, which are connected to each other via virtual openings. Flights are modeled as slopes, and the slope angle and direction of the floor are given using unit gradient vectors. In the space in each cell, the evacuee specifies the opening between the landing and the flight as the destination. All the spaces in a multi-story building are reproduced by connecting stories via staircase.

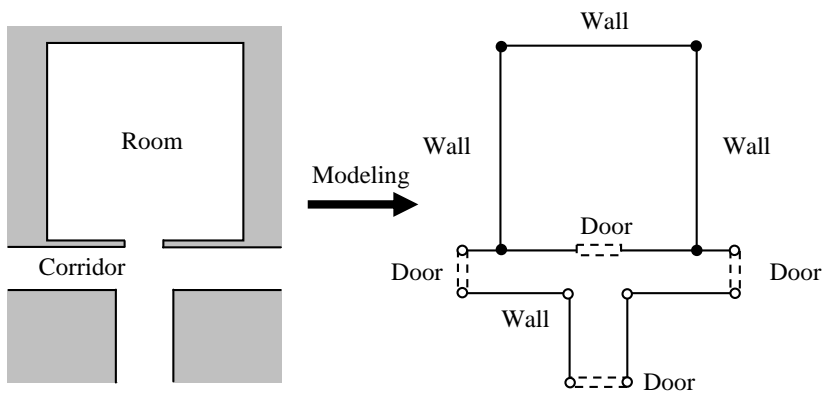

Fig. 4. Concept of modeling of space.

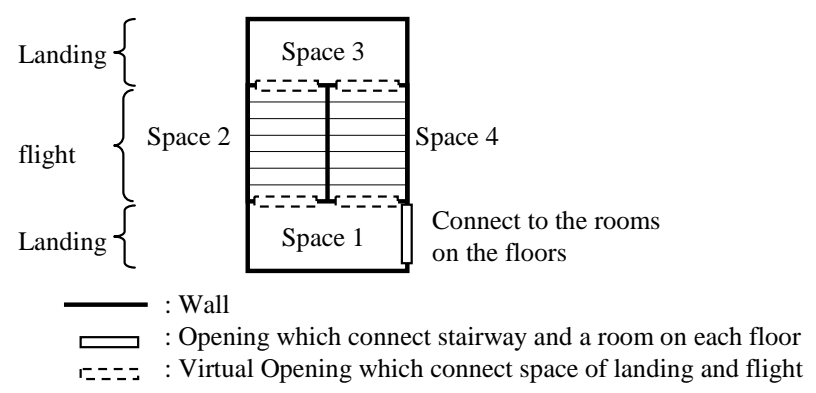

Fig. 5. Modeling of space in staircase.

\section{Human Model}

In the human model, behavioral parameters of the evacuee are controlled and the destination of each evacuee, and the direction and target of movement are determined. The area occupied by the evacuee is modeled as a circle with the diameter identical to the shoulder length of the occupant. Behavioral parameters in evacuation such as the walking speed, selection of escape route and the need of help during escape can be set arbitrarily for each evacuee. Evacuees are classified into four categories according to the characteristics of selection of escape route.

- Type I: Decides the direction of movement arbitrarily based on the information available in the room

- Type II: Has a full knowledge about the escape routes in the building and decides the direction of movement arbitrarily

-Type III: Follows instructions given by emergency evacuation light

- Type IV: Follows other evacuees

When predicting behavior in evacuation, it is assumed that the evacuee first selects the destination based on the position information at the specific point of time and determines the direction and target of movement according to the destination. Two types of destinations have been defined.

-Long-term destination: Place where the evacuee wants to take area of refuge finally.

- Short-term destination: Immediate destination such as the exit or emergency evacuation light before finally reaching the long-term destination. 
The evacuee continues escape while selecting short-term destinations to finally reach the long-term destination. The evacuee is not advised of the location of the long-term destination at the start of escape. Destinations are a) final area of refuge, b) exit, c) emergency evacuation light showing the direction of movement, and d) door in the descending order of priority. Destinations are set for each evacuee and at each time step. Information on destinations and obstacles are controlled separately in each space in the space model. The evacuee except type II occupant can not obtain any information other than that on the space in which he or she is located.

How the evacuee determines the direction and target of movement is shown in Fig.6. The direction of movement is determined by modeling with vectors of the multiple forces acting on the evacuee such as the destinations, surrounding walls, obstacles and other evacuees. When combining vectors, force of inertia in the direction of movement is given to simulate human movement as realistically as possible. The evacuee is subject to attraction from destinations and repulsion from surrounding walls, obstacles and other evacuees. Repulsive vector is in inverse proportion to the distance between the evacuee and the object.

If several evacuees have to move the same position at the next calculation step, the evacuees search alternative position to prevent the collision. The vector indicating the direction of movement is shifted at every 15 degrees to the right and left sides and the position where no collision occurs is determined for the next step.

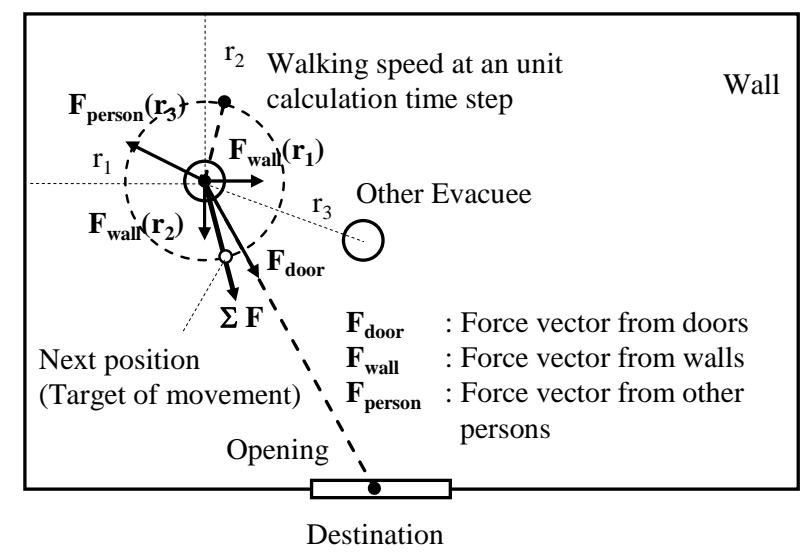

Fig.6. How the evacuee determines the direction and target of movement.

The target of movement is determined for each time step based on the direction of movement identified through vectorial sum, density of people and the walking speed of the evacuee. The walking speed is reduced if the density of people around the evacuee increases. The density of people around the evacuee is calculated in a semicircle with a radius of $3.0 \mathrm{~m}$ in the direction of movement. The relationship between the density of people and walking speed is expressed by the Eq.1 [9].

$$
V=\min \left(V_{0}, \frac{V_{0}}{\rho}\right)
$$

\section{Smoke Model}

The smoke model is used to control the data on the height and temperature of the smoke layer in each room output by a smoke movement simulation model such as BRI2002[10], and to provide information on the condition of smoke in each space in the space model as time passes in simulation. The smoke movement simulation model and evacuation models are independent of each other. Smoke movement in the building is calculated specifying the time for the fire protection system to be operated or the duration in which doors are left open according to a pre-designated scenario. The following effects of smoke flow on evacuation can be considered.

\section{a) Limit state of egress}

Limit state of egress expresses the state in which the height of smoke layer is less than $1.8 \mathrm{~m}$ and the temperature of smoke layer reaches above a reference level in the Eq.2 [10] 
$\int_{t_{s}}^{t_{e}}(\Delta T)^{2} d t \geq 10,000$

After the room reaches the limit state of egress, the evacuees in the room can no longer continue escape. Evacuees in the other rooms, where the smoke condition does not reach the limit state of egress, can neither use the room in the limit state of egress as an escape route nor enter it.

\section{b) Start of evacuation}

Evacuees start evacuation from the room when the height of smoke layer lowers below a certain level (e.g. $90 \%$ of the ceiling height).

\section{c) Specification of destination}

Emergency evacuation light showing the direction of movement is no longer identifiable when the smoke layer lowers below the height of the evacuation light and the smoke concentration exceeds a reference level of $0.3 / \mathrm{m}$. Evacuation is expected to affect smoke movement. For example, the opening and closing doors during escape may cause the spread of smoke. In this model, however, this effect of evacuation on smoke movement is pre-determined in simulating smoke movement.

\section{CASE STUDY}

\section{Purpose of Case Study}

As we have very good data from the survey of human behavior along with the condition of fire growth and smoke spread in a real fatal fire of the Nagasakiya Store, so we first tried to reproduce the evacuation situation of this fire as accurately as possible reflecting the facts from the survey by applying our evacuation and smoke movement interactive model. Then, after confirming the reproducibility of the model, we examined possible changes of consequences of evacuation using our simulation model according to different egress scenarios in order to find possible future issues and solutions for the problems regarding the total evacuation in a multi-story building.

\section{Three Conditions for Calculation}

Three case studies were conducted to verify the usefulness of the evacuation and smoke movement interactive model and to examine possible changes of consequences according to different egress scenarios.

\section{Four Cases for Calculation}

Case-1: The case to reproduce of the Amagasaki Store fire to verify the calculated results with the model. And, therefore, the egress scenario was set according as the facts investigated through the interview survey.

Case-2: The case to examine the possible change of consequences, if the occupants on the $5^{\text {th }}$ floor had started their evacuation earlier at 12:35, 5 minutes after the fire outbreak, when the thin smoke was perceived in the corridor on the $5^{\text {th }}$ floor. But, the number of occupants was not changed from the real fire case.

Case-3: The case to examine the possible change of consequences in addition to the change in Case-2, if the number of occupants was set based on the standard of calculation method to verify evacuation safety, which is established in Building Standard Law of Japan. In the standard, occupant density for the department store is set at 0.5 persons $/ \mathrm{m}^{2}$, which corresponds to the period of bargain sales.

Case-4: The case to examine the possible change of consequences in addition to the change in Case- 3 , if the occupants had started their evacuation earlier. If the staffs of the store guided the evacuation more efficiently, occupants could start the evacuation earlier. Occupants on the $4^{\text {th }}$ floor had started to evacuate at 12:32, two minutes after the fire outbreak and ones on the other floors had started to evacuate at 12:34, four minutes after the fire outbreak.

Evacuation conditions for the four cases such as the numbers of evacuees and when they started evacuation are listed in Table 1. The mean walking speed of evacuees was set at 1.0 meter per second, which was also designated as the standard walking speed designated in the calculation method to verify evacuation safety in the Building Standard Law. The travel walking speed of each evacuee varied randomly from 0.8 to 1.2 meters per second. 
Table 1. Numbers of evacuees and time to start evacuation as a precondition to the three cases examined.

\begin{tabular}{|c|c|c|c|c|c|c|}
\hline \multirow[b]{2}{*}{ Floor } & \multirow[t]{2}{*}{ Occupancies } & \multicolumn{3}{|c|}{$\begin{array}{l}\text { Time to start evacuation } \\
\text { after the outbreak of fire }\end{array}$} & \multicolumn{2}{|c|}{$\begin{array}{l}\text { Number of Evacuees } \\
\text { at the outbreak of fire }\end{array}$} \\
\hline & & Case-1 & $\begin{array}{l}\text { Case-2 } \\
\text { Case-3 }\end{array}$ & Case-4 & $\begin{array}{l}\text { Case-1 } \\
\text { Case-2 }\end{array}$ & $\begin{array}{l}\text { Case-3 } \\
\text { Case-4 }\end{array}$ \\
\hline \multirow[t]{3}{*}{$5^{\text {th }}$ floor } & Game arcade & \multirow[t]{3}{*}{$8 \mathrm{~min}}$. & \multirow[t]{3}{*}{5 min. } & \multirow[t]{3}{*}{$4 \mathrm{~min}}$. & 5 & 5 \\
\hline & Office & & & & 2 & 2 \\
\hline & Employee dining room & & & & 14 & 55 \\
\hline $4^{\text {th }}$ floor & $\begin{array}{l}\text { Wear store } \\
\text { Home furnishing store }\end{array}$ & $4 \mathrm{~min}$. & 4 min. & $2 \mathrm{~min}$. & 20 & 313 \\
\hline $3^{\text {rd }}$ floor & Wear store & 5 min. & 5 min. & $4 \mathrm{~min}$. & 30 & 313 \\
\hline $2^{\text {nd }}$ floor & Wear store & 6 min. & 5 min. & $4 \mathrm{~min}$. & 30 & 313 \\
\hline $1^{\text {st }}$ floor & $\begin{array}{l}\text { Daily miscellaneous goods } \\
\text { store cosmetics store }\end{array}$ & $6 \mathrm{~min}$. & $5 \mathrm{~min}$. & $4 \mathrm{~min}$. & 30 & 334 \\
\hline & & Total & & & 131 & 1335 \\
\hline
\end{tabular}

\section{Fire and Environmental Conditions}

Fire and environmental conditions were set based on the reports on the fire[7,8] for modeling the space in the building, and for calculating the aggravation of fire and start time of evacuation. Smoke movement in the building was calculated using BRI2002. The fire broke out in the sales space of bedding on the $4^{\text {th }}$ floor. The fire source was modeled as the Eq.3.

$Q=\alpha\left(t-t_{0}\right)^{2}$

No employee noticed the fire when a fire detector detected it at 120 seconds after it broke out. Then, the fire was regarded as non-flaming burning until 90 seconds passed after it started and $t_{0}$ was expressed by 90 sec. Flame reached the ceiling at 180 seconds after the outbreak of fire, or 90 seconds after flaming. Fire growth rate was set at $0.083 \mathrm{~kW} / \mathrm{sec}^{2}$ and $Q_{\max }$ at $25 \mathrm{MW}$ (640 sec) so that the height of intermittent flame could reach the height of ceiling $(2.7 \mathrm{~m})$ in 180 seconds after the outbreak of fire. The outside temperature is set at $12^{\circ} \mathrm{C}$ and the outdoor wind velocity is $9 \mathrm{~m} / \mathrm{sec}$ from west-southwest direction.

\section{RESULTS AND DISCUSSION}

\section{Case-1: Reproduction of the Consequences of the Nagasakiya Store Fire}

The fire occurred near the sales space of bedding on the $4^{\text {th }}$ floor and spread throughout the floor in about ten minutes. The heat and smoke entered the $5^{\text {th }}$ floor and also the third and lower floors via two staircases and elevator shafts. Occupants on the $5^{\text {th }}$ floor failed to start evacuation early and were forced to take refuge on the floor. High-temperature smoke spread to the $5^{\text {th }}$ floor and killed fifteen occupants in the real fire case.

In Table 2, we showed the results of smoke propagation time, exposure starting time to the smoke layer and limit time for evacuation, which was calculated with our model for each area such as sales floor space, the north side working place, the north and the south staircases on the $4^{\text {th }}$ floor and the dining room and the corridor on the $5^{\text {th }}$ floor respectively.

The table shows that when people on the $5^{\text {th }}$ floor tried to start their evacuation eight minutes after a fire ignition as derived from the interview survey, the corridor on the $5^{\text {th }}$ floor was already polluted by this moment with the smoke which propagated from the staircase-S, and it also passed the limit time for evacuation (450 seconds after the ignition). Therefore, the calculation result well reproduced the fire condition of the real situation, in which people could not go out from the dining room to the corridor so that they had no other choice than being trapped there.

The calculated limit time for evacuation due to the untenable condition in the staircase- $\mathrm{N}$ is 595 seconds after the fire ignition. This result very well agreed with the witness of the security guard who went up to the $4^{\text {th }}$ floor from the first floor in the real fire. When he reached the $4^{\text {th }}$ floor and tried to use the fire 
hydrant, the fire suddenly expanded and the black smoke began to flow into the staircase- $\mathrm{N}$ at a stretch, which was seemed to occur around 10 minutes (600 seconds) after the fire outbreak on the $4^{\text {th }}$ floor.

The numbers of evacuees who used the escalator and the staircase-S for evacuation on the $2^{\text {nd }}$ floor through $4^{\text {th }}$ floor are shown in Fig.7. Most of the $4^{\text {th }}$ floor occupants were led by sales clerks to evacuate via escalator section. Calculation results show that all completed escape from the $4^{\text {th }}$ floor at 310 seconds after the fire outbreak, while the escalator section on the $4^{\text {th }}$ floor were exposed to smoke 330 seconds after the outbreak of fire and later.

Table 2. Calculation results of smoke impacts for the reproduced case of the Nagasakiya Store fire.

\begin{tabular}{|c|c|c|c|c|c|}
\hline Place & Floor & $\begin{array}{l}\text { Time in second } \\
\text { to smoke } \\
\text { propagation, } \\
\text { where smoke } \\
\text { temperature }< \\
100^{\circ} \mathrm{C} \\
\end{array}$ & $\begin{array}{l}\text { Time in second } \\
\text { to smoke } \\
\text { temperature } \\
\text { rise to } 100^{\circ} \mathrm{C}\end{array}$ & $\begin{array}{l}\text { Time in second } \\
\text { to the smoke } \\
\text { exposure, } \\
\text { where height of } \\
\text { smoke layer }> \\
1.8 \mathrm{~m}\end{array}$ & $\begin{array}{l}\text { Time in second } \\
\text { to the limit of } \\
\text { evacuation, } \\
\text { where height of } \\
\text { smoke layer } \\
<1.8 \mathrm{~m}\end{array}$ \\
\hline Corridor & \multirow{4}{*}{$5^{\text {th }}$ floor } & 325 & - & 360 & 450 \\
\hline Dining room & & 360 & -- & 435 & 1070 \\
\hline $\begin{array}{l}\text { Emergency office } \\
\text { room }\end{array}$ & & 360 & - & 430 & - \\
\hline Working area & & 365 & - & 570 & 675 \\
\hline Sales floor & \multirow[t]{2}{*}{$4^{\text {th }}$ floor } & 90 & 195 & 425 & 425 \\
\hline Working area & & 285 & 545 & 545 & 545 \\
\hline \multirow{2}{*}{ North staircase } & $5^{\text {th }}$ floor & 420 & - & 430 & 595 \\
\hline & $4^{\text {th }}$ floor & 440 & - & 450 & 595 \\
\hline \multirow[t]{2}{*}{ South staircase } & $5^{\text {th }}$ floor & 295 & - & 310 & 405 \\
\hline & $4^{\text {th }}$ floor & 325 & - & 350 & 405 \\
\hline Escalator & $4^{\text {th }}$ floor & 200 & 285 & 330 & 330 \\
\hline
\end{tabular}

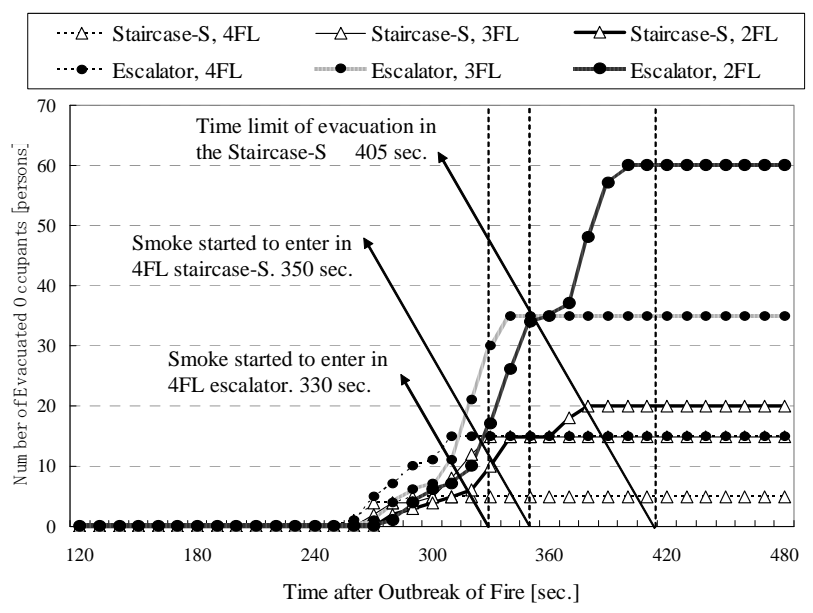

Fig.7. Number of cumulative evacuees on the second floor through fourth floor for the Case-1.

\section{Case-2: The Case if the Occupants on the $5^{\text {th }}$ Floor Started Their Evacuation Earlier}

In the Nagasakiya Store fire, although many occupants on the $5^{\text {th }}$ floor had a chance to go downstairs even after the notice of the fire, they failed to evacuate because they were not properly told about the fire threat by the staff of the emergency service office. Therefore, in Case-2, we changed the condition of starting time of evacuation earlier on the $5^{\text {th }}$ floor in order to examine how the consequences of evacuation was 
impacted by this change. Here, we tried to see the effect of proper guidance of evacuation, if the occupants on the $5^{\text {th }}$ floor had started their evacuation at 12:35, 5 minutes after the fire outbreak, when the thin smoke was perceived in the corridor on the $5^{\text {th }}$ floor in the real fire as shown in Fig.2. Another change of calculation conditions was no use of escalators for evacuation, since it is usually prohibited to use escalators in fire situation. But, the number of occupants was not changed from the real fire case.

Fig.8 shows the cumulative numbers of evacuees who used the staircase- $\mathrm{N}$ and the staircase-S on the $4^{\text {th }}$ and $5^{\text {th }}$ floors respectively. The numbers of occupants on the $5^{\text {th }}$ floor and $4^{\text {th }}$ floor were only 21 and 20 respectively, so all of them safely escaped through the two staircases far before the time limit of untenable condition in the both staircases. As for the staircase-S, the occupants from the $5^{\text {th }}$ floor and the $4^{\text {th }}$ floor completed their evacuation at 370 seconds after the fire outbreak, while the staircase-S on the $4^{\text {th }}$ floor was exposed to the smoke and to become untenable at 405 seconds, which was 35 seconds later than the completion of escape. Also, as for the staircase- $\mathrm{N}$, the evacuation completion time on the $4^{\text {th }}$ floor was 360 seconds after the fire outbreak that was much earlier than the limit time of evacuation due to the untenable condition by smoke exposure on the $4^{\text {th }}$ floor at 595 seconds after the fire outbreak.

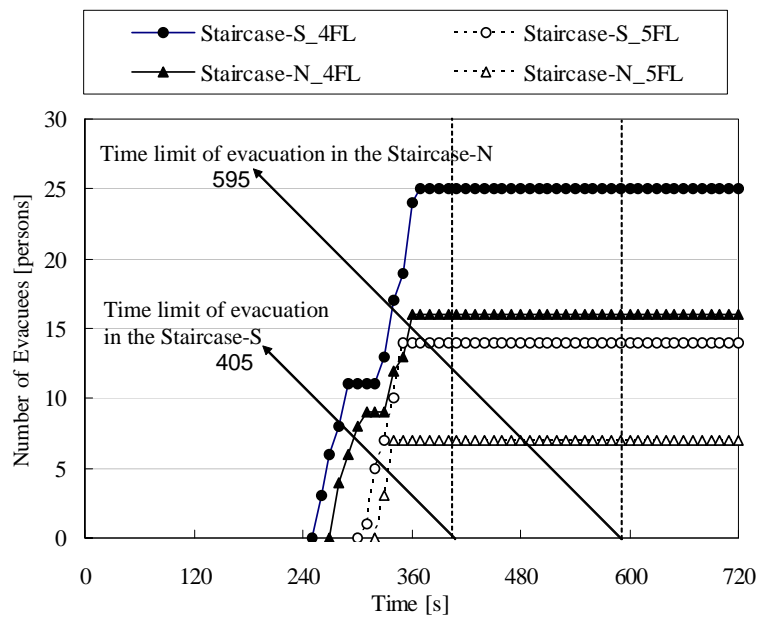

Fig.8. Number of cumulative evacuees by time lapse for the Case-2.

\section{Case-3: The Case if the Occupants Load Was Set Based on the Standard in Evacuation Safety Verification Method in Building Standard Law in Japan}

In Case-3, we changed simply one condition from the Case-2, which is the density of occupants to see the impact of heavy occupant load to the consequences. The number of occupants was determined based on the standard of calculation method to verify evacuation safety, which is designated in Building Standard Law of Japan. In the standard, for example, occupant density for the department store is set at 0.5 persons $/ \mathrm{m}^{2}$, which corresponds to the period of bargain sales and accordingly the total number of occupants was set to be almost ten times larger than that in the real fire case, as seen in Table 1.

From Fig.9, we see the numbers of fatalities suddenly started to grow and to be kept as 86 and 37 just after the time limit of untenable condition in the staircase-S at 405 and the staircase- $\mathrm{N}$ at 595 seconds after the fire outbreak respectively, as these number of evacuees were trapped there due to the congestion in the staircases. Similarly, the cumulative numbers of fatalities on the $4^{\text {th }}$ floor started to grow and to be kept 120 just after the time limit of untenable condition on the $4^{\text {th }}$ floor at 425 seconds after the fire outbreak, because these occupants were exposed to the smoke while waiting for entering to the staircases. By contrast, the occupants on the $5^{\text {th }}$ floor escaped safely because the occupant load was not so much changed as it was mainly used for employees only on that floor.

As a result, it was found that the Amagasaki Store fire would cause 243 fatalities in total, which is $18.2 \%$ of the total number of occupants, if the occupant load is set based on the standard of the evacuation safety verification method designated by Building Standard Law in Japan and the evacuation is done using 
staircases as usually directed. This result demonstrates that the capacity of existing two staircase are not enough to assure the safe evacuation for occupants, if the total evacuation is needed in the most busy season such as a bargain sales period. For this problem, the installation of sprinkler system would be a best solution even though the total building area is roughly 5,000 $\mathrm{m} 2$ and not so large, since there is very few alternative ways to resolve it.

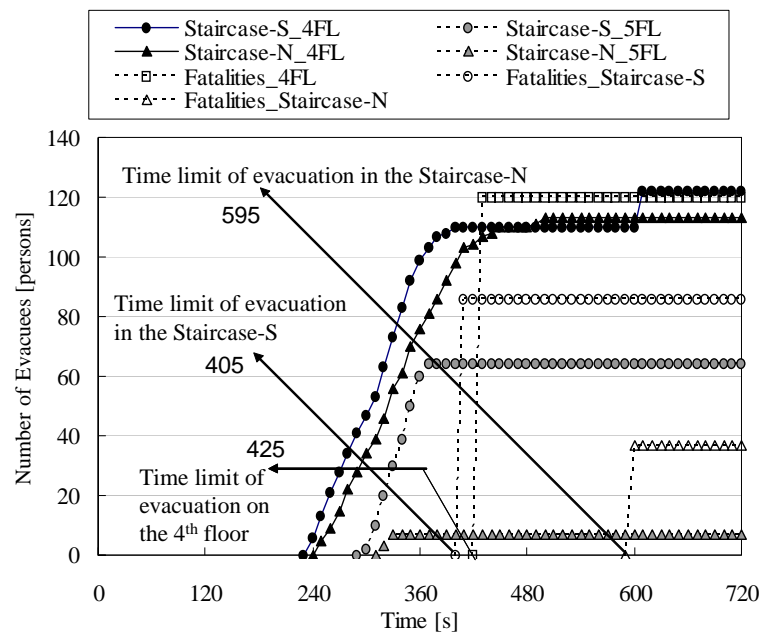

Fig.9. Number of cumulative evacuees and fatalities by time lapse for the Case-3.

\section{Case-4: The Case if the Occupants on the Every Floor Started Their Evacuation Earlier}

In Case-4, we changed the condition from Case-3 to examine sensitivity of a parameter for evacuation starting time. On the $4^{\text {th }}$ floor, all occupants started evacuation at $12: 32$, when the emergency bell was just worked. On the other floors, evacuation was started at 12:34, which is one minute later after a call from employee on the $4^{\text {th }}$ floor to the staff room on the $5^{\text {th }}$ floor.

Figure 10 shows the simulated results of evacuation for Case-4. As a result, 31 and 81 fatalities were caused on the $4^{\text {th }}$ floor and in the staircase-S, respectively. Compared with the results for Case- 3 , a number of fatalities in Case- 4 decreased from 243 to 112 persons in total. It was found that the time to start evacuation at early stage of the fire was very sensitive to the number of fatalities. Reliable evacuation guidance will be an effective measure to ensure the life safety of occupants in the department store.

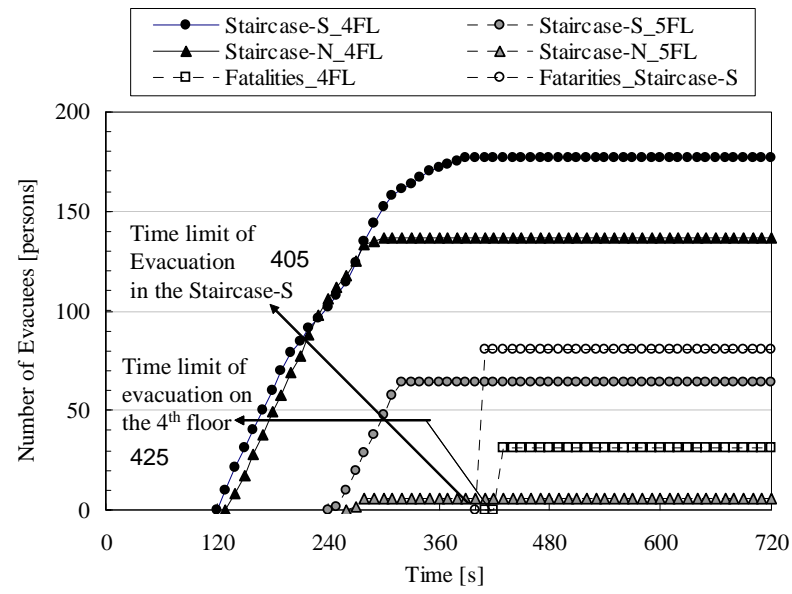

Fig.10. Number of cumulative evacuees and fatalities by time lapse for the Case-4. 


\section{CONCLUDING REMARKS}

The evacuation and smoke movement interactive simulation model has been developed to handle the evacuation of large populations of individuals with mixed walking capabilities in a multi-story building via staircases in consideration of interactions between egress behavior and spread of smoke in a building. Using this simulation model, we conducted case studies to reproduce the smoke condition and evacuation situation of a real fatal fire of the 1990 Nagasakiya Store fire as accurately as possible reflecting the facts from the survey. The calculated results of case studies well agreed with the investigated pattern of risk in evacuation behavior linked with the smoke impacts by the model. We also demonstrated that our simulation model is useful enough to examine possible changes of consequences according to different egress scenarios in order to find possible future issues and solutions for the problems regarding the total evacuation in a multi-story building.

\section{ACKNOWLEDGMENT}

We would like to express our sincere gratitude for the assistance provided by Dr. Atsushi Ohwaki of Digital Network in the development of the evacuation model and by Mr. Hiroaki Notake at Institute of Technology, Shimizu Corporation in making this paper possible.

\section{REFERENCES}

[1] Fahy, R.F. and Proulx, G., "Human Behavior in the World Trade Center Evacuation," Fire Safety Science - Proceedings of the 5th International Symposium, International Association for Fire Safety Science, 1997, pp.713-724. doi:10.3801/IAFSS.FSS.5-713

[2] Owen, M., Gaela, E.R., and Lawrence, P., “Advanced Occupant Behavioural Features of the Building-EXODUS Evacuation Model," Fire Safety Science - Proceedings of the 5th International Symposium, International Association for Fire Safety Science, 1997, pp.795-806. doi:10.3801/IAFSS.FSS.5-795

[3] Thompson, P.A. and Marchant, E.W., "Simulex: Developing New Computer Modelling Techniques for Evacuation," Fire Safety Science - Proceedings of the 4th International Symposium, International Association for Fire Safety Science, 1994, pp.613-624. doi:10.3801/IAFSS.FSS.4-613

[4] Kakegawa, S., Yashiro, Y. and Ebihara, M., "Life Safety Evaluation of Large Populations with Mixed-Abilities,” 13th Joint Panel Meeting on Fire Research and Safety, U.S./Japan Government Cooperative Program on Natural Resources, Volume 1., 1997, pp.27-34. doi:10.3801/IAFSS.FSS.4-645

[5] Kakegawa, S., Yashiro, Y., Ebihara, M. and Ohtsuki, A., "Evaluation of Fire Safety Measures in Care Facilities for the Elderly by Simulating Evacuation Behavior,” Fire Safety Science Proceedings of the 4th International Symposium, International Association for Fire Safety Science, 1994, pp.645-656.

[6] Kakegawa, S., Notake, H., Sekizawa, A., and Ebihara, M., "Evaluation and Smoke Movement Interactive Simulation Model,” Proceedings of the 7th Asia-Oceania Symposium on Fire Science and Technology, 2007, published in CD.

[7] Amagasaki Fire Department, “Fire of Amagasaki Store of Nagasakiya,” Kasai, Journal of Japan Association for Fire Science and Engineering, Vol.40, No.3, 1990, pp.2-5 (in Japanese).

[8] Sekizawa, A., "Fire of Amagasaki Store of Nagasakiya and Evacuation Behavior during the Fire,” Proceedings of the Symposium on Human Behavior in Fires and Evaluation of Life Safety against Fire - How occupants response to the fire, 2000, pp.21-31 (in Japanese).

[9] Togawa, K. ," Study on Fire Escapes basing on the Observation of Multitude Currents,” Report of the Building Research Institute, No.14, Feb. 1955 (in Japanese).

[10] Tanaka, T. and Yamada, S., “BRI2002: Two Layer Zone Smoke Transport Model”, Fire Science and Technology, Center for Fire Science and Technology, Tokyo University of Science, Vol.23, No.1 (Special Issue), 2004, pp.1-131. 